\title{
Relationship between past airway pathology and current lung function in preschool wheezers
}

\author{
S. Sonnappa*,\#, C.M. Bastardo*, S. Saglani", A. Bush" and P. Aurora*\#
}

ABSTRACT: The functional outcome in preschool severe wheezers with eosinophilic airway inflammation and increased reticular basement membrane (RBM) thickness is unknown. We investigated the relationship between airway pathology at age 2 yrs and lung function at age 46 yrs in previous severe wheezers.

Severe wheezers previously investigated by endobronchial biopsy and healthy children aged 46 yrs were recruited. Lung clearance index ( $\mathrm{LCl})$, conducting zone ventilation inhomogeneity (Scond), acinar ventilation inhomogeneity by multiple-breath washout, plethysmographic-specific airway resistance and exhaled nitric oxide fraction ( $\mathrm{FeNO}$ ) were measured. Lung function was compared between wheezers and healthy controls, and in wheezers correlated with past RBM thickness and mucosal eosinophilia (EG2+ cells).

72 healthy controls and 28 previous severe wheezers were tested. Wheezers had significantly higher median LCI (6.8 versus $6.6 ; p=0.001)$ and Scond $(0.046$ versus $0.016 ; p<0.0005)$ than healthy controls. Past RBM thickness $(r=0.474, p=0.047)$ and $E G 2+$ cells $(r=0.552, p=0.041)$ showed significant correlations with current $F$ eNO, but no correlations were seen between past RBM thickness and current lung function.

RBM thickness and EG2+ cells at age 2 yrs show a significant positive association with $F$ eNO at age 5 yrs. Although lung function was abnormal at age 5 yrs in severe wheezers, this did not correlate with past RBM thickness.

KEYWORDS: Children, eosinophilia, exhaled nitric oxide fraction, lung function, preschool wheeze, reticular basement membrane thickness

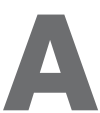
sthma comprises different phenotypes that manifest with similar clinical symptoms. Established risk factors for the development of asthma in childhood include frequent wheezing during the first 3 years of life, a parental history of asthma, personal history of eczema, allergic rhinitis, wheezing apart from colds, peripheral blood eosinophilia of $\geqslant 4 \%$ and early allergic sensitisation to perennial aeroallergens [1, 2]. Some, but not all, early wheezers have worsening of lung function, asthma symptoms or both over time [3]. However, the physiological consequences of pathological changes in the asthmatic airways are poorly understood. While some adult studies show that increased reticular basement membrane (RBM) thickness is associated with airway obstruction [4], others show that RBM thickening is protective against bronchoconstriction $[5,6]$. Contemporaneous studies of pathology and function in preschool children with recurrent wheeze are lacking, due to ethical concerns over performing endobronchial biopsies and preschool lung function testing being limited to specialist centres.

We recently reported that preschool children with multiple-trigger wheeze have abnormal lung function whilst those with episodic (viral) wheeze do not, irrespective of atopic and current wheeze status [7]. In a subgroup of these children with severe recurrent wheeze, SAGLANI et al. [8] previously performed endobronchial biopsies at a median age of 29 months. They showed evidence of increased RBM thickness and mucosal eosinophilic inflammation (EG2+ cells) in wheezers compared with nonwheezing controls, which was less severe than that seen in adult asthmatics [8] We hypothesised that in preschool children with

This article has supplementary material available from www.erj.ersjournals.com

AFFILIATIONS

*Portex Unit, Respiratory Medicine and Physiology, University College London Institute of Child Health,

\# Dept of Respiratory Medicine, Great Ormond Street Hospital for Children NHS Trust, and

'Dept of Paediatric Respiratory Medicine, Royal Brompton Hospital and Imperial College, London, UK

\section{CORRESPONDENCE}

S. Sonnappa

Portex Unit, Respiratory Medicine and Physiology

UCL Institute of Child Health and Great Ormond Street Hospital for Children

30 Guilford Street

London

WC1N 1EH

UK

E-mail: s.sonnappa@ich.ucl.ac.uk

Received:

Oct 212010

Accepted after revision:

June 142011

First published online:

July 202011 


\begin{tabular}{|c|c|c|}
\hline TABLE 1 & \multicolumn{2}{|c|}{$\begin{array}{l}\text { Definitions according to wheeze status used in } \\
\text { the current study }\end{array}$} \\
\hline Status & & Definition \\
\hline \multicolumn{3}{|c|}{ Symptom-pattern status } \\
\hline \multicolumn{2}{|c|}{ Episodic (viral) wheeze } & $\begin{array}{c}\text { "Wheezing during discrete time periods, often } \\
\text { in association with clinical evidence of a viral } \\
\text { cold, with absence of wheeze between } \\
\text { episodes" [11] }\end{array}$ \\
\hline \multicolumn{2}{|c|}{ Multiple-trigger wheeze } & $\begin{array}{l}\text { "Wheezing that shows discrete exacerbations, } \\
\text { but also symptoms between episodes" triggered } \\
\text { by dust, cold air, exercise, laughter, etc. [11] }\end{array}$ \\
\hline \multicolumn{3}{|c|}{ Atopic status } \\
\hline \multicolumn{2}{|c|}{ Atopic wheeze } & $\begin{array}{l}\text { Wheezer who is skin-prick test-positive and/or } \\
\text { has current eczema }\end{array}$ \\
\hline \multicolumn{2}{|c|}{ Nonatopic wheeze } & $\begin{array}{l}\text { Wheezer who is skin-prick test-negative and has } \\
\text { no eczema }\end{array}$ \\
\hline \multicolumn{3}{|c|}{ Current wheeze status } \\
\hline \multicolumn{2}{|c|}{ Current symptomatic } & $\begin{array}{l}\text { Wheezer with a history of at least one wheezing } \\
\text { episode in the past } 12 \text { months }\end{array}$ \\
\hline \multicolumn{2}{|c|}{ Current asymptomatic } & $\begin{array}{l}\text { Wheezer with no wheezing episodes in the past } \\
\qquad 12 \text { months }\end{array}$ \\
\hline
\end{tabular}

previous severe recurrent wheeze, past RBM thickness would show a negative association with current lung function, and mucosal eosinophilic inflammation would show a positive association with an indirect measure of eosinophilic inflammation, namely exhaled nitric oxide fraction $(\mathrm{FeNO})$, and a positive association with current wheeze. Therefore, we investigated the relationship between current lung function, FeNO and past endobronchial biopsy findings in this unique cohort, and related these findings to current wheeze phenotype and symptoms.

\section{METHODS}

This cross-sectional study was conducted at the University College London (UCL) Institute of Child Health (London, UK) and was approved by the Joint UCL/UCL Hospital Ethics
Committee. All subjects underwent clinical and lung function assessments, as previously described [7]. Briefly, the assessments included: FeNO measured at an expiratory flow of $50 \mathrm{~mL} \cdot \mathrm{s}^{-1}$ using the single-breath online method according to the American Thoracic Society/European Respiratory Society guidelines [9], with computerised equipment and a chemiluminescence analyser (CLD 88; EcoMedics, Durnten, Switzerland); multiple-breath washout (MBW) indices (lung clearance index (LCI), a measure of overall ventilation inhomogeneity, and conducting zone contribution to ventilation inhomogeneity (Scond) and acinar zone contribution to ventilation inhomogeneity (Sacin)), measured by using sulfur hexafluoride as the inert marker gas; and plethysmographic specific airway resistance (sRaw). The FeNO measurements reported in this study are after adjusting for the best plateau for a 6-s exhalation [10]. Atopic sensitisation was ascertained by skin-prick tests to house dust mite, cat, dog, grass, tree and Aspergillus fumigatus (Soluprick SQ; ALK-Abello A/S, Horsholm, Denmark); sensitisation was defined as a wheal $\geqslant 3 \mathrm{~mm}$ greater than the negative control.

The children were reclassified at the study visit in three different ways, according to current wheeze status (table 1). Subgroup analysis was performed on each of these threepaired categories. FeNO and lung function measurements were correlated with past RBM thickness and EG2+ cells (biopsy methods as previously reported) $[8,12]$ in all wheezers and in the wheeze subgroups. By definition, the severe preschool wheezers were between 3 months and 5 yrs of age, and had at least three episodes of wheeze lasting $>3$ days in the previous 6 months [8]. For brevity, previous severe wheezers will be referred to as "wheezers", irrespective of current wheeze status, throughout this article, except where specifying wheeze status according to the classification in table 1 .

\section{Statistical analysis}

Sample size was opportunistic, being determined by the number of children originally enrolled who agreed to return for follow-up. Multivariable linear regression was used to compare the differences in pulmonary function between wheezers and healthy controls after adjustment for birth and current weight, age and height. Due to skewness, the outcome

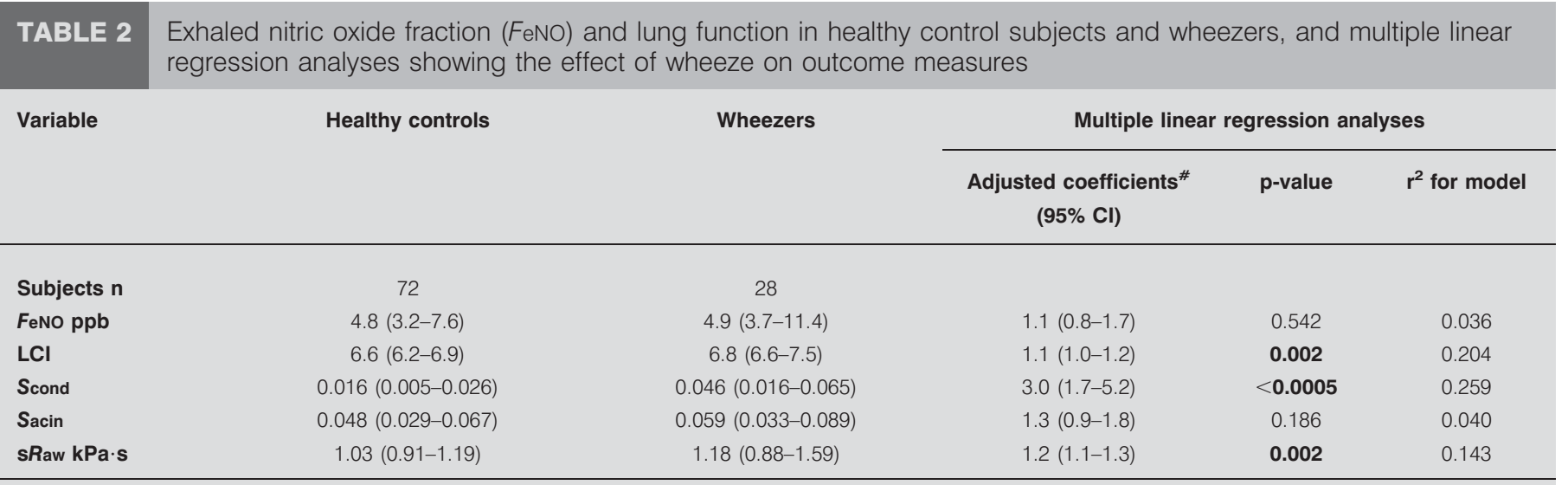

Data are presented as median (interquartile range), unless otherwise stated. Bold indicates statistical significance. LCI: lung clearance index; Scond: conducting zone contribution to ventilation inhomogeneity; Sacin: acinar zone contribution to ventilation inhomogeneity; sRaw: specific airway resisance. ${ }^{\#}$ : coefficients were exponentiated and represent the multiplicative effect of wheeze on $\mathrm{FeNO}$ and lung function outcome. 


\begin{tabular}{|c|c|c|c|c|c|c|}
\hline TABLE 3 & $\begin{array}{l}\text { Correlations between } \\
\text { membrane (RBM) thi }\end{array}$ & $\begin{array}{l}\text { ent exhaled n } \\
\text { ss and EG2+ }\end{array}$ & ide frac & ) and lun & with past $r$ & sement \\
\hline \multirow[t]{2}{*}{ Variable } & \multicolumn{3}{|c|}{ RBM thickness } & \multicolumn{3}{|c|}{ EG2+ cells } \\
\hline & RBM thickness & Wheezers ${ }^{\#}$ n & $p$-value & EG2+ cells & Wheezers ${ }^{\#}$ n & $\mathrm{p}$-value \\
\hline FenO & 0.474 & 18 & 0.047 & 0.552 & 14 & 0.041 \\
\hline Scond & 0.135 & 21 & 0.559 & 0.009 & 16 & 0.974 \\
\hline Sacin & -0.106 & 21 & 0.647 & -0.128 & 16 & 0.637 \\
\hline
\end{tabular}

Data are presented as Pearson correlation coefficient, unless otherwise stated. Bold indicates statistical significance. sRaw: specific airway resistance; LCl: lung clearance index; Scond: conducting zone contribution to ventilation inhomogeneity; Sacin: acinar zone contribution to ventilation inhomogeneity. ${ }^{*}$ : with both pathology and outcome data for that variable.

variables were log-transformed and adjusted coefficients with 95\% confidence intervals are reported. Lung function and FeNO data were log-transformed to investigate the associations between past pathology findings by the Pearson correlation test. Subgroups of wheezers were compared by using Chi-squared or Mann-Whitney U-tests, as appropriate. A 5\% level of significance was considered statistically significant.

\section{RESULTS}

The original "severe wheeze" cohort consisted of 47 wheezers [8], of whom 28 children (60\%; 16 males) consented to take part in the current study at median age 5.0 yrs (interquartile range (IQR) 4.4-5.9 yrs). 72 healthy controls (37 males; median age 5.5 yrs, IQR 5.1-6.2 yrs) were also recruited [7]. All 28 wheezers were able to perform MBW and sRaw measurements, and FeNO measurement was successful in 22 children. RBM thickness measurements were available for 22 (79\%) out of 28 children, and data relating to biopsy EG2+ cells were available for $17(61 \%)$ out of 28 children. The median age at which biopsy was performed in the wheezers recruited to the current study was $2.1 \mathrm{yrs}$ (IQR 1.1-3.4 yrs) and the median interval from endobronchial biopsy to lung function testing was $3.1 \mathrm{yrs}$ (IQR 2.7-3.6 yrs).



Of the 28 wheezers, $23(82 \%)$ were prescribed inhaled corticosteroid (ICS) in the past. Of these, 15 (65\%) children were currently prescribed ICS with equivalent daily doses of beclomethasone ranging 200-800 $\mu$ g. Eight of these children were prescribed longacting bronchodilators, four were prescribed leukotriene receptor antagonists and four were prescribed antireflux medication (ranitidine or omeprazole and domperidone).

The wheezers had significantly higher LCI, Scond and sRaw compared with healthy controls, but there was no difference in FeNO (table 2).

\section{Relationship between past airway pathology and current airway function}

There was a significant positive correlation between past RBM thickness and EG2+ cells with current FeNO (table 3 and fig. 1). However, past RBM thickness and EG2+ cells were not associated with current lung function (table 3). On exploring these associations further in the current subgroups of episodic (viral) and multiple-trigger, atopic and nonatopic, and current symptomatic and asymptomatic wheeze, no significant associations were found between past biopsy findings and current FeNO or lung function.

b)

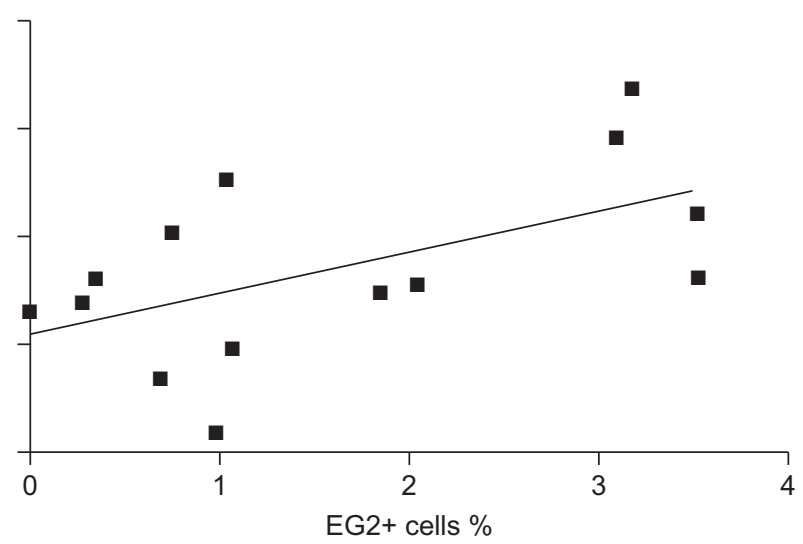

FIGURE 1. Positive relationship of current exhaled nitric oxide fraction ( $F$ eNO) with a) past reticular basement membrane $(\mathrm{RBM})$ thickness $(r=0.474, p=0.047)$ and b) $E G 2+$ cells $(r=0.552, p=0.041)$. 



FIGURE 2. Comparison of $a, c, e)$ reticular basement membrane (RBM) thickness and b, d, f) EG2+ cells between wheeze phenotypes at a median age of 5 yrs: a, b) current episodic (viral) and multiple-trigger wheezers; c, d) current nonatopic and atopic wheezers; and e, f) current asymptomatic and symptomatic wheezers. - : median for each subgroup.

\section{Past airway pathology and current airway function according to current wheeze phenotype}

RBM was significantly thicker and EG2+ cells were significantly greater in current multiple-trigger wheezers compared with episodic (viral) wheezers (online supplementary table S1 and fig. 2). Current multiple-trigger wheezers also had significantly higher FeNO, LCI and Scond than current episodic (viral) wheezers despite significantly more multiple-trigger wheezers being currently prescribed ICS (online supplementary table S1).

There was no difference in FeNO, lung function and past RBM thickness or EG2+ cells between the current atopic versus nonatopic wheezers (online supplementary table S2 and fig. 2).
Current asymptomatic wheezers showed a significantly higher Sacin than symptomatic wheezers and there was a strong trend for past EG2+ cells to be elevated in current symptomatic wheezers compared with asymptomatic wheezers, but there were no other differences (online supplementary table S3 and fig. 2).

\section{DISCUSSION}

This is the first study to investigate the association between past airway inflammation, RBM thickness and lung function, and current symptoms in preschool children with previous severe wheeze. We found that elevation in RBM thickness and EG2+ cells at a median age of 2 yrs show a significant positive association with $\mathrm{FeNO}$ at a median age of 5 yrs. Lung function was significantly abnormal in the previous severe wheezers 
compared with healthy controls, but there was no association between past RBM thickness and current lung function. There was a strong trend for wheezers with elevated EG2+ cells at a median age of 2 yrs to be symptomatic at a median age of 5 yrs.

SAGLANI et al. [8] showed contemporaneously that the RBM was significantly thicker in multiple-trigger wheezers compared with episodic (viral) wheezers. Similarly, another study showed that children with multiple-trigger wheeze have significantly increased RBM thickness and EG2+ cells, irrespective of age and atopic status [13]. It is interesting to note that this difference remains with retrospective rephenotyping even after 3 yrs, irrespective of the presence or absence of symptoms.

There is a positive correlation between FeNO and eosinophilic airway inflammation in adult and paediatric asthmatics when measured contemporaneously [14, 15], and the relationship is better in steroid-naïve patients. However, the present study is the first to find an association between directly measured eosinophilic airway inflammation at a median age of 2 yrs and FeNO at a median age of 5 yrs, in preschool wheezers. Furthermore, the strong trend for current symptomatic wheezers to have had increased EG2+ cells compared with asymptomatic wheezers suggests that airway inflammation present at age 2 yrs can persist 3 yrs later, despite prescribed ICS treatment. Nonetheless, this is speculative as there was no second direct measurement of eosinophilic inflammation and the relationship is weaker in children using ICS, as in this study. However, we did not think it ethical to stop their prescribed treatment. The relationship may be the result of poor treatment compliance, poor delivery of inhaled medication to the airway or because ICS are ineffective or only partly effective in modulating inflammation at this age. Our findings give pathological insights into the findings of the Prevention of Early Asthma in Kids (PEAK) and Inhaled Fluticasone Propionate in Wheezy Infants (IFWIN) studies [16, 17], in which very early regular administration of ICS failed to modify the progression of asthma. We speculate that children in these studies who went on to wheeze persistently had underlying eosinophilic airway inflammation, which could not be reversed by the prescribed ICS.

The lack of an association of past RBM thickness with wheeze persisting at age 5 yrs and lung function is in agreement with studies in older children and adults with asthma that were unable to demonstrate a relationship between RBM thickness, duration and severity of asthma [18, 19] and lung function $[18,20]$. Indeed, it has been proposed that RBM thickening may be protective rather than deleterious $[5,6]$. Although our failure to show a relationship between RBM thickness and impaired lung function may be a power issue, it is also compatible with the view that increased RBM thickness does not have adverse physiological effects [6].

Ethical concerns preclude conducting an invasive longitudinal contemporaneous study investigating the functional consequences of structural changes in children. The sample size and noncontemporaneous nature of our study limits meaningful interpretation of the lack of differences and correlations for most of the biopsy findings. A further limitation is that airway smooth muscle thickness was not measured in our biopsies. Studies in older children [21] and adults [22] with severe asthma have shown an association with increased smooth muscle thickness and impairment of lung function. The lung function tests used in this study were comprehensive by including measures of global ventilation inhomogeneity (LCI), conducting zone (Scond) and acinar zone (Sacin) contributions to ventilation inhomogeneity, and sRaw, a measure of airway resistance mainly contributed from the central airways. Nonetheless, the endobronchial biopsies were taken from the subsegmental carina, and it is uncertain whether pathological changes in the central airways reflect changes in the smaller and peripheral airways in young children, and whether these, in turn, are reflected by the physiological measures chosen in this study. However, several studies suggest that airway inflammation occurs throughout the airway [23, 24], and in adults, it has been demonstrated that RBM thickening in the central airways is related to RBM thickening in all cartilaginous airways, including the smaller cartilaginous airways, but not the peripheral membranous airways [25]. There are no such data in preschoolers. The conclusions, therefore, are more hypothesis generating than definitive. Allowing for these limitations, these are unique data evaluating the relationship between early pathological changes in the airway and later physiological outcomes in preschool children with severe wheeze.

In summary, we have demonstrated that increased RBM thickness and mucosal eosinophilia at a median age of $2 \mathrm{yrs}$ shows a significant positive association with $F$ eNO at a median age of $5 \mathrm{yrs}$, in a group of preschool children with severe wheeze. Although lung function was abnormal in these wheezers at a median age of 5 yrs, there was no correlation between deficits in lung function and past RBM thickness or eosinophilia. RBM thickness at a median age of 2 yrs did not predict the presence or absence of wheeze at a median age of 5 yrs, but there was a trend for elevated mucosal eosinophilia at a median age of $2 \mathrm{yrs}$ to be associated with persistence of wheeze at a median age of 5 yrs.

\section{SUPPORT STATEMENT}

This study was supported by Asthma UK, the European Respiratory Society and Smiths Medical.

\section{STATEMENT OF INTEREST}

A statement of interest for the study itself can be found at www.erj. ersjournals.com/site/misc/statements.xhtml

\section{ACKNOWLEDGEMENTS}

The authors thank all the parents and children who participated in the study.

\section{REFERENCES}

1 Castro-Rodriguez JA, Holberg CJ, Wright AL, et al. A clinical index to define risk of asthma in young children with recurrent wheezing. Am J Respir Crit Care Med 2000; 162: 1403-1406.

2 Illi S, von Mutius E, Lau S, et al. Perennial allergen sensitisation early in life and chronic asthma in children: a birth cohort study. Lancet 2006; 368: 763-770.

3 Panettieri RA Jr, Covar R, Grant E, et al. Natural history of asthma: persistence versus progression-does the beginning predict the end? J Allergy Clin Immunol 2008; 121: 607-613.

4 Kasahara K, Shiba K, Ozawa T, et al. Correlation between the bronchial subepithelial layer and whole airway wall thickness in patients with asthma. Thorax 2002; 57: 242-246. 
5 Payne DN, Qiu Y, Zhu J, et al. Airway inflammation in children with difficult asthma: relationships with airflow limitation and persistent symptoms. Thorax 2004; 59: 862-869.

6 Milanese M, Crimi E, Scordamaglia A, et al. On the functional consequences of bronchial basement membrane thickening. J Appl Physiol 2001; 91: 1035-1040.

7 Sonnappa S, Bastardo CM, Wade A, et al. Symptom-pattern phenotype and pulmonary function in preschool wheezers. J Allergy Clin Immunol 2010; 126: 519-526.

8 Saglani S, Payne DN, Zhu J, et al. Early detection of airway wall remodeling and eosinophilic inflammation in preschool wheezers. Am J Respir Crit Care Med 2007; 176: 858-864.

9 American Thoracic Society, European Respiratory Society. ATS/ ERS recommendations for standardized procedures for the online and offline measurement of exhaled lower respiratory nitric oxide and nasal nitric oxide, 2005. Am J Respir Crit Care Med 2005; 171 : 912-930.

10 Sonnappa S, Bastardo CM, Bush A, et al. Exhaled nitric oxide measurements from different analysers. Chest 2010; 138: 1275-1277.

11 Brand PL, Baraldi E, Bisgaard H, et al. Definition, assessment and treatment of wheezing disorders in preschool children: an evidence-based approach. Eur Respir J 2008; 32: 1096-1110.

12 Saglani S, Nicholson AG, Scallan M, et al. Investigation of young children with severe recurrent wheeze: any clinical benefit? Eur Respir J 2006; 27: 29-35.

13 Turato G, Barbato A, Baraldo S, et al. Nonatopic children with multitrigger wheezing have airway pathology comparable to atopic asthma. Am J Respir Crit Care Med 2008; 178: 476-482.

14 Brightling CE, Symon FA, Birring SS, et al. Comparison of airway immunopathology of eosinophilic bronchitis and asthma. Thorax 2003; 58: 528-532.
15 Silkoff PE, Lent AM, Busacker AA, et al. Exhaled nitric oxide identifies the persistent eosinophilic phenotype in severe refractory asthma. J Allergy Clin Immunol 2005; 116: 1249-1255.

16 Guilbert TW, Morgan WJ, Zeiger RS, et al. Long-term inhaled corticosteroids in preschool children at high risk for asthma. N Engl J Med 2006; 354: 1985-1997.

17 Murray CS, Woodcock A, Langley SJ, et al. Secondary prevention of asthma by the use of Inhaled Fluticasone propionate in Wheezy INfants (IFWIN): double-blind, randomised, controlled study. Lancet 2006; 368: 754-762.

18 Payne DN, Rogers AV, Adelroth E, et al. Early thickening of the reticular basement membrane in children with difficult asthma. Am J Respir Crit Care Med 2003; 167: 78-82.

19 Bai TR, Cooper J, Koelmeyer T, et al. The effect of age and duration of disease on airway structure in fatal asthma. Am J Respir Crit Care Med 2000; 162: 663-669.

20 Chu HW, Halliday JL, Martin RJ, et al. Collagen deposition in large airways may not differentiate severe asthma from milder forms of the disease. Am J Respir Crit Care Med 1998; 158: 1936-1944.

21 Tillie-Leblond I, de Blic J, Jaubert F, et al. Airway remodeling is correlated with obstruction in children with severe asthma. Allergy 2008; 63: 533-541.

22 Benayoun L, Druilhe A, Dombret MC, et al. Airway structural alterations selectively associated with severe asthma. Am J Respir Crit Care Med 2003; 167: 1360-1368.

23 Tashkin DP. The role of small airway inflammation in asthma. Allergy Asthma Proc 2002; 23: 233-242.

24 Carroll N, Elliot J, Morton A, et al. The structure of large and small airways in nonfatal and fatal asthma. Am Rev Respir Dis 1993; 147: 405-410.

25 James AL, Maxwell PS, Pearce-Pinto G, et al. The relationship of reticular basement membrane thickness to airway wall remodeling in asthma. Am J Respir Crit Care Med 2002; 166: 1590-1595. 